\title{
A simplified modification of a reconstruction plate into a mandibular transport distraction device: A technical note
}

\author{
Sujata Mohanty, Jitender Dabas, Rekha Gupta ${ }^{1}$ \\ Departments of Oral and Maxillofacial Surgery and ${ }^{1}$ Prosthodontics, Maulana Azad Institute of Dental Sciences, \\ New Delhi, India
}

Address for correspondence: Dr. Sujata Mohanty, Department of Oral and Maxillofacial Surgery, Maulana Azad Institute of Dental Sciences, New Delhi, India. E-mail: drsm28@gmail.com

\section{ABSTRACT}

Transport distraction is nowadays gaining enormous popularity and is becoming a promising option for reconstruction of mandibular defects. However, the vast number of distraction device designs create huge confusion in the clinician's mind to choose the right one. Considering these complex and costly designs, the authors decided to find a simplified way of combining a modified conventional reconstruction plate and monofocal distraction device that can act as a transport distraction device for bridging of bony defects. A case performed by this technique and device has been presented along with the description of device design.

\section{KEY WORDS}

Devices; mandibular reconstruction; transport distraction

\section{INTRODUCTION}

$\angle$ ransport distraction osteogenesis (DO) has become a popular reconstruction method for bony defects created after resection or traumatic bone loss. ${ }^{[1]}$ This technique is more complicated and sensitive than monofocal DO. First, Constantino used this for mandibular reconstruction in a canine model ${ }^{[2]}$ and thereafter in human mandible. ${ }^{[3]}$ This led to an increased interest of the surgeons in developing devices which could transport the bony segment across the defect.

Literature is saturated with reports of diverse variety of transport devices with different designs, each one claiming

\begin{tabular}{|l|l|}
\hline \multicolumn{2}{|c|}{ Access this article online } \\
\hline Quick Response Code: & Website: \\
\hline & www.ijps.org \\
\hline & \\
\hline
\end{tabular}

their superiority over the other, but none has found universal acceptance, and results of most of them have been reported only in small case series. Although every report mentions pluses of a particular device, they have some common minuses which include complex designs and associated increased cost. This cost rises even higher in cases requiring customized fabrication of the device. The authors are presenting a unique way of combining a standard $2.4 \mathrm{~mm}$ reconstruction plate with a monofocal distraction device in order to bridge mandibular bony defects. This combination avoids use of costly and bulky

\footnotetext{
This is an open access article distributed under the terms of the Creative Commons Attribution-NonCommercial-ShareAlike 3.0 License, which allows others to remix, tweak, and build upon the work non-commercially, as long as the author is credited and the new creations are licensed under the identical terms.
}

For reprints contact: reprints@medknow.com

How to cite this article: Mohanty S, Dabas J, Gupta R. A
simplified modification of a reconstruction plate into a mandibular
transport distraction device: A technical note. Indian J Plast Surg
$2015 ; 48: 313-6$. 
transport distraction devices which are more complicated and quite uncomfortable for the patient.

\section{Device design}

A standard $2.4 \mathrm{~mm}$ mandibular reconstruction plate was modified to act as fixation device as well as for creating channel for movement of Molina distractors [Figure 1]. The metal bridges between the screw holes were cut as per the desired length, thus creating a linear channel in the middle through which the distractor pins could move without any hindrance.

\section{CASE REPORT}

After resecting an anterior mandibular ameloblastoma in a 54-year-old patient, trifocal distraction was performed using the modified reconstruction plate described earlier [Figure 2]. After tumour resection, the plate was fixed in conventional manner across the defect with the help of two bi-cortical screws on either side. These screws were placed in the third and fourth hole from the planned transport disc osteotomy end. Then, the transport disc segments of adequate length were osteotomized from the healthy bone on either side.

Two distractor pins were then fixed in the residual bone immediately adjacent to the transport disc osteotomy, and two pins were fixed in the transport disc. On either side, Molina distractors were then fixed in the conventional manner. The pins in transport segment were positioned in such a way that they lie within the linear cut in the reconstruction plate [Figure 1]. After a latency period of 7 days, the device was activated at a rate of $1 \mathrm{~mm} /$ day and rhythm of twice daily till the transport discs contacted each other in the midline. Care was taken to fix the reconstruction plate in the middle of residual bone rather than the lower border in order to have proper control over the vector of distraction. In this way, the reconstruction plate could act as a guide for movement of the distractor pins along with the transport bone segment.

Forty millimetre distraction was done on each side. The duration of consolidation was approximately 120 days (4 months). During the consolidation period, maxillo-mandibular fixation (MMF) was done by direct wiring and barrel bandage to provide additional support and stability to the distracted segments and chin. After completion of the consolidation period, bone regeneration was seen in the defect site with the alignment of bony trabeculae along the direction of distraction [Figure 3].

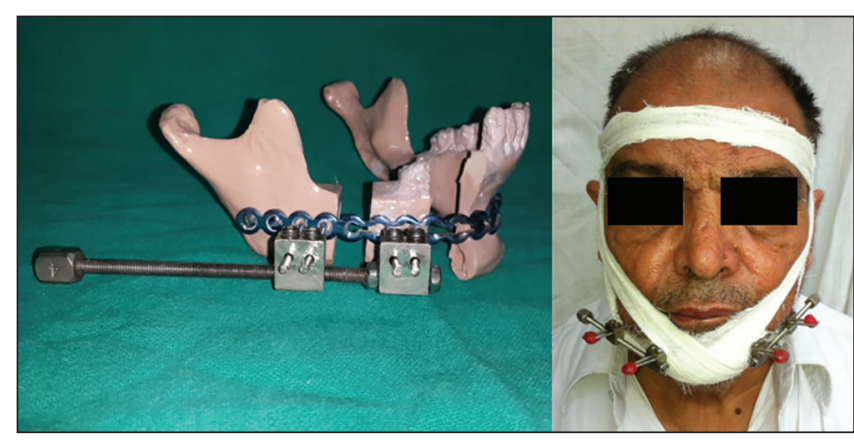

Figure 1: Figure showing the modified reconstruction plate and device design with the device insitu

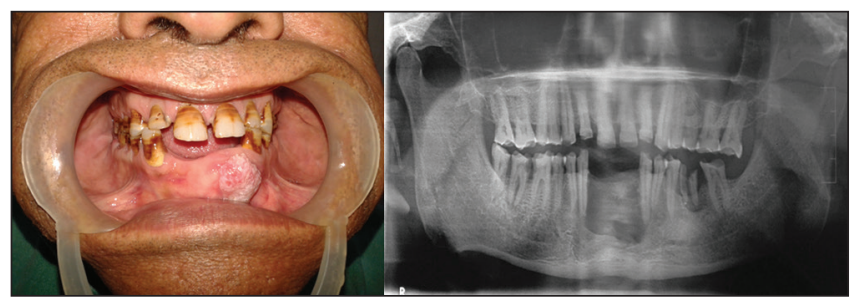

Figure 2: Pre-operative clinical and radiographic images of the patient

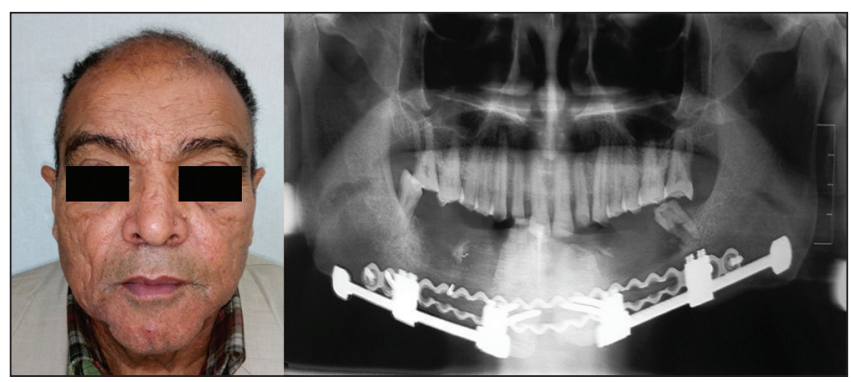

Figure 3: Post-operative clinical and radiographic images of the patient

Coronal computed tomography (CT) slices showed bone formation with a density of D2 to D3 at the distraction sites [Figure 4]. In the second surgery, the fibrous caps on the leading edges of distracted segments in the symphysis region were resected and the defect was filled with deep freeze dried bone allograft (DFDBA). After completion of the consolidation period, the distraction device was removed, whereas the reconstruction plate was left in situ in view of additional support to the distracted segments. Prosthetic rehabilitation of the patient was done by using the existing teeth as overdenture abutments. Parallelism of abutments was achieved by placing metal copings over the teeth and the overdenture was fabricated in the mandibular arch [Figure 5].

\section{DISCUSSION}

Mandibular transport distraction, in contrast to monofocal distraction, presents a more complex situation. In order to achieve good vector control and to make the transport 
disc move in a curvilinear fashion, the earlier distraction devices consisted of a U-shaped extra-oral frame which remained attached to the transport segment with extraoral pins perpendicular to the frame. But these devices were extremely bulky and unacceptable to the patient. The distraction device used by Constantino (1995) consisted of an external semicircular frame attached to the mandible by two pairs of pins and to the transport disc by a transport tram. However, this frame was also quite bulky. ${ }^{[3]}$ Since in our device, the reconstruction plate itself acts as the U-shaped frame, the bulk of device is much less and it is more comfortable for the patient. Herford, ${ }^{[4]}$ Guerrero, ${ }^{[5]} \mathrm{Hibi}$ and Ueda $^{[6]}$ came up with intra-oral devices in order to avoid the social embarrassment associated with bulky extra-oral devices. But as mentioned by Andrade et al., ${ }^{[1]}$ these devices are costly and usually out of reach for many patients in the economically poor or developing countries. So, there is an ongoing quest for devices which can perform the function satisfactorily at an affordable cost. In our device, the design, placement and functioning are technically simple. The supero-inferior vector control is well taken care of by the strategical placement of reconstruction plate and distractor pins in the middle. However, the authors found that it is difficult to move the transport disc in the anterior curvature of the mandible region. This problem can be solved by using trifocal distraction with two transport discs moving from both sides and meeting each other in the middle [Figure 6]. This results in a V'-shaped arch rather than a ' $U$ '-shaped arch with a resultant defect in the middle. In the presented case, the authors dealt with this

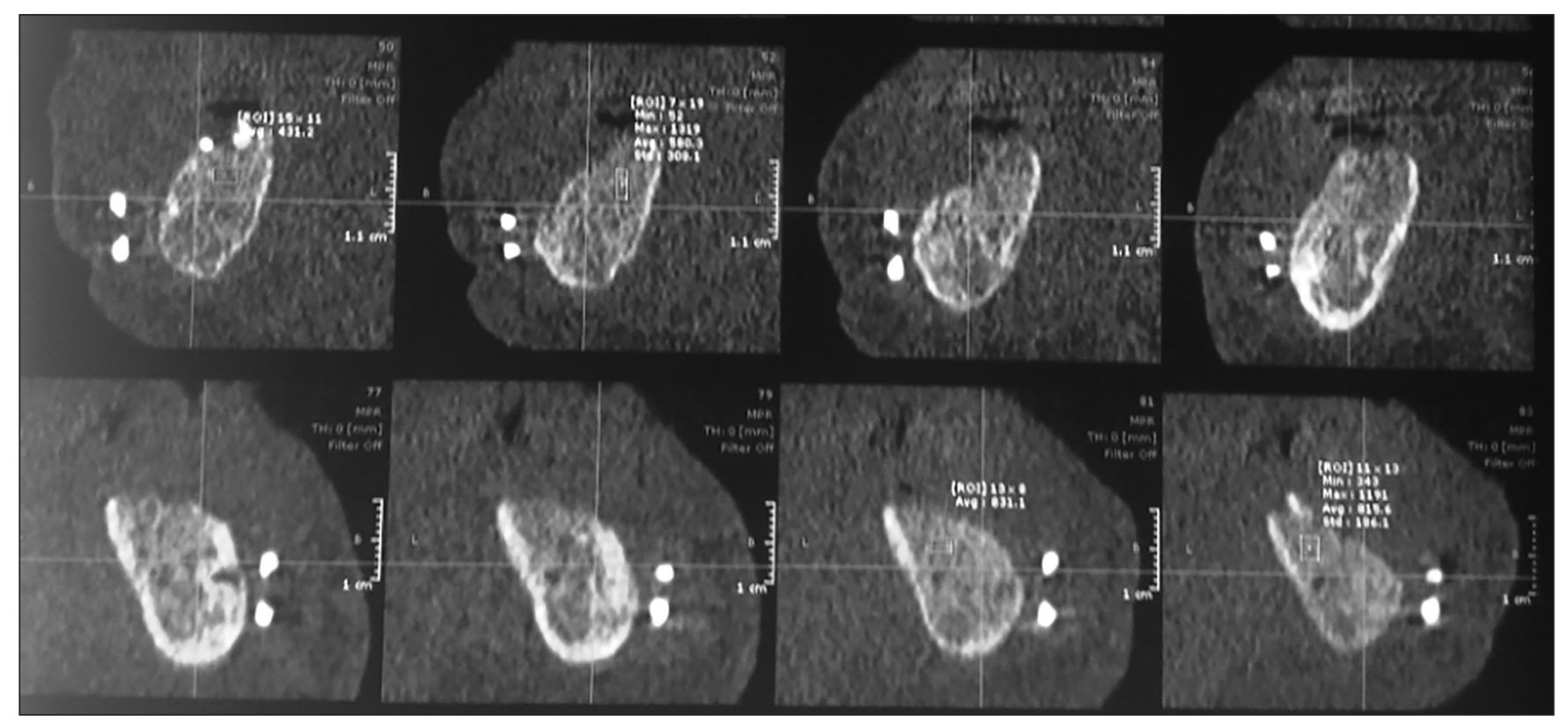

Figure 4: Coronal section of the bilateral distraction sites showing the quality of bone formed

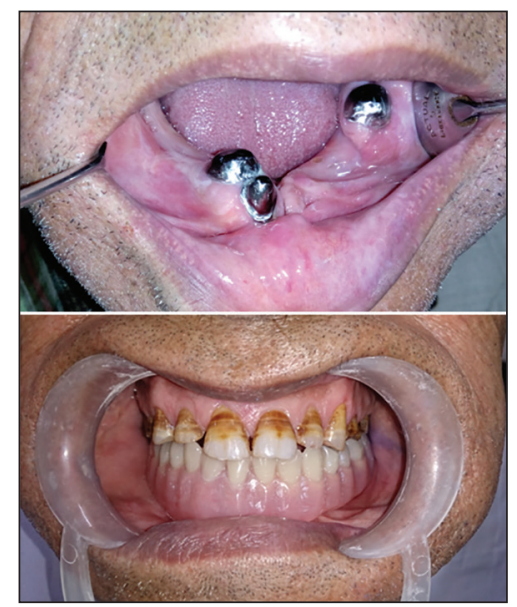

Figure 5: Figure showing prosthetic rehabilitation with the abutment teeth and the overdenture in place

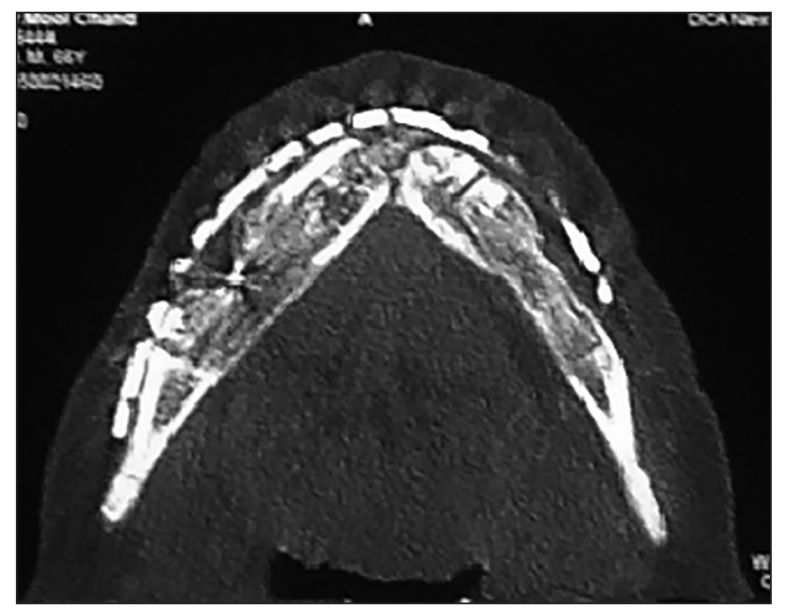

Figure 6: Figure showing the quality and quantity of the regenerate. The transport discs are meeting in the midline 
problem with secondary grafting with DFDBA via intra-oral approach. The technique is more suitable for linear defects of the mandible. Another advantage of the device is that removal of device can be done under local anaesthesia with minimal invasive surgery leaving the reconstruction plate in situ. The authors found this device satisfactory for bridging large mandibular defects.

\section{Declaration of Patient Consent}

The authors certify that they have obtained all appropriate patient consent forms. In the form the patient(s) has/have given his/her/their consent for his/her/ their images and other clinical information to be reported in the journal. The patients understand that their names and initials will not be published and due efforts will be made to conceal their identity, but anonymity cannot be guaranteed.

\section{Financial support and sponsorship}

Nil.

\section{Conflicts of interest}

There are no conflicts of interest.

\section{REFERENCES}

1. Andrade N, Gandhewar T, Kalra R. Development and evolution of distraction devices: Use of indigenous appliances for Distraction Osteogenesis-An overview. Ann Maxillofac Surg 2011;1:58-65.

2. Costantino PD, Friedman CD. Distraction osteogenesis: Applications for mandibular regrowth. Otolaryngol Clin North Am 1991;24:1433-43.

3. Costantino PD, Johnson CS, Friedman CD, Sisson GA Sr. Bone regeneration within a human segmental mandible defect: A preliminary report. Am J Otolaryngol 1995;16:56-65.

4. Herford AS. Use of a plate-guided distraction device for transport distraction osteogenesis of the mandible. J Oral Maxillofac Surg 2004;62:412-20.

5. Guerrero CA. Expansion rapida mandibular. Rev Venez Ortod 1990;12:48.

6. Hibi H, Ueda M. New internal transport distraction device for reconstructing segmental defects of the mandible. $\mathrm{Br} \mathrm{J}$ Oral Maxillofac Surg 2006;44:382-5. 